\title{
Planejamento de carreira para alunos e egressos de graduações em Design de Moda: necessidade e relevância
}

Career planning for undergraduate students and alumni in Fashion
Design: need and relevance

LIMA, Cláudia Cyléia de

Universidade do Estado de Santa Catarina - UDESC I claudiacyleia@hotmail.com

SILVEIRA, Icléia

Universidade do Estado de Santa Catarina - UDESC I icleiasilveira@gmail.com

RECH, Sandra Regina

Universidade do Estado de Santa Catarina - UDESC I sandra.rech@udesc.br

BEIRÃO FILHO, José Alfredo

Universidade do Estado de Santa Catarina - UDESC I jbeiraofilho@gmail.com

\begin{abstract}
Resumo
Investiga-se a necessidade e a relevância do planejamento de carreira para alunos e egressos de graduações em Design de Moda. Após pesquisa quali-quantitativa e descritiva, subsidiada por questionário aplicado em pesquisa de campo, os resultados apontam a carência e a importância de orientações, obtidas ainda na graduação, sobre mercado, possibilidades profissionais e planejamento de carreira na área em questão.
\end{abstract}

Palavras-chave: Moda. Design. Carreira. Formação superior.

\section{Abstract}

The need and relevance of career planning for undergraduate and graduate students in Fashion Design is investigated in this study. After the conduction of a quali-quantitative and descriptive research, supported by the application of an infield questionnaire, results suggest the lack and the importance of guidelines - which must be provided during the undergraduate course - on market, professional possibilities, and career planning about the Fashion Design field.

Keywords: Fashion. Design. Career. Higher education. 


\section{INTRODUC̣ÃO}

O estudo que originou este artigo faz parte de uma pesquisa de Mestrado em andamento. As questões discutidas correspondem a problemas reais enfrentados na prática docente, na busca pela aprendizagem que possibilite ao egresso construir uma carreira marcada pelo exercício pleno da profissão.

Atuando em graduações em Design de Moda na região Nordeste do Brasil, mais precisamente no estado do Piauí, onde o primeiro curso superior na área foi implantado em 2008, surgiram inquietações sobre alunos e egressos que apresentam dúvidas relativas à carreira e ao mercado de trabalho.

De início, esta realidade foi percebida por uma das autoras deste artigo na primeira turma de Design de Moda, na então Faculdade NOVAFAPI, hoje Centro Universitário, por relatos informais de colegas. Depois, como docente na mesma instituição, na Universidade Federal do Piauí (UFPI), e posteriormente no Instituto Federal do Piauí (IFPI-Campus Piripiri).

Vale ressaltar que não se tratava de casos isolados ou angústias comuns à vida universitária. Foram diversas mensagens encaminhadas via e-mail pessoal, telefone celular e mídias sociais da pesquisadora. Em sua maioria, perguntas a respeito de que caminhos seguir no mercado, e que iam desde a precificação de serviços até onde distribuir currículos, chegando a "pedidos" de avaliação de projetos profissionais ou opiniões sobre cursos.

A repetição dessas mensagens sugere a urgência de atitudes que contribuam positivamente com a situação. Deduz-se que ela tem e terá repercussões negativas, com efeitos sociais e econômicos, podendo levar à criação de falsas expectativas, frustrações pessoais e profissionais, evasão universitária e, em última instância, à extinção de cursos.

Nesse sentido, surgiram hipóteses que associavam esta realidade à ausência parcial ou total, nos cursos de graduação ofertados no estado, de disciplinas ou atividades voltadas ao conhecimento das profissões e ao planejamento de carreira na área de Moda. Assim, para averiguar se tal ausência compromete a formação dos graduados em Design de Moda, esta pesquisa pretende investigar, sob a perspectiva de alunos e egressos, a necessidade e a importância das atividades de planejamento de carreira, executadas durante a graduação.

Para atingir este objetivo, adotou-se abordagem quantitativa e descritiva, subsidiada por um questionário aplicado em pesquisa de campo. A coleta de dados foi feita em pesquisa documental, com a análise das matrizes 
curriculares dos cursos de Design de Moda existentes no estado do Piauí, e de um questionário online', disponível no período entre março e setembro de 2017.

Cientificamente, o trabalho justifica-se pela superação da lacuna nas publicações sobre planejamento de carreira em Moda. Por ter fins práticos, pretende contribuir para solucionar problemas aplicando resultados em instituições de ensino. Socialmente, mostra-se relevante por oferecer subsídios para compreender a realidade pesquisada, visando consequências positivas no contexto socioeconômico, e no desenvolvimento profissional e humano dos alunos. No âmbito pessoal, os autores pretendem oferecer contribuições aos estudantes, bem como à área em que atuam profissionalmente.

A seguir, articulam-se alguns posicionamentos dos autores consultados para a fundamentação teórica do artigo. A pesquisa bibliográfica abordou formação superior, profissões no mercado de Moda e conceitos relativos ao planejamento de carreira.

\section{AS PROFISSÕES LIGADAS À MODA}

\subsection{A Formação Superior}

Os cursos superiores de Moda foram instituídos no Brasil na década de 1980. A exigência de formação específica foi, entre outros fatores, a resposta de um mercado crescente no qual atuavam profissionais com outras formações, e que já não eram suficientes diante das demandas às quais a área era submetida.

De acordo com Pires (2002, p. 2), a criação do primeiro curso superior de Moda em São Paulo, no ano de 1988, e das pós-graduações na década seguinte, estão ligadas ao crescimento econômico no período, à instalação de indústrias de fiação, de têxteis e de confecção de vestuário, bem como à política de abertura de mercado e ao surgimento de muitas escolas de moda no hemisfério Norte.

Após o surgimento das graduações no Sudeste, foi a vez das regiões Sul e Nordeste criarem cursos superiores de Moda, nas universidades de Caxias do Sul - UCS, em 1993, e Federal do Ceará - UFC, no ano de 1994. O Brasil é o país com maior número de graduações em moda no mundo: 180 cursos cadastrados no e-MEC (Cadastro de Instituições e Cursos de Educação Superior) do Ministério da Educação, conforme dados de setembro de 2017.

1 Pesquisa:formação, carreiraemercado detrabalhoem Modanoestadodo Piauí. Disponível em: https://docs.google.com/forms/d/1aGIBZDxhYBQ5-cP6dTtwYnTGt9fSF8q8FFDOlaQiJ2g/ edit. 
LIMA, Cláudia Cyléia de; et al.

Segundo Puls (2010, p. 7), até o começo do século XXI a academia trabalhava na perspectiva do Estilismo e não do Design, e o Estilista era visto como um "criador com formação acadêmica". Posteriormente surgiram esforços para formar outro perfil, o do Designer capaz de entender as linguagens entre a universidade e o mercado de trabalho, sendo objetivo das instituições de ensino a formação humana, social e profissional.

Neste contexto, a denominação "Design de Moda" é utilizada por 85\% das graduações ofertadas no Brasil, como aponta a análise realizada por Baggio (2017). Tal análise também constatou a predominância do grau acadêmico tecnológico, contabilizando $70 \%$ dos cursos superiores na área e destoando do contexto geral do ensino superior brasileiro, onde são maioria os bacharelados e as licenciaturas.

Para Baggio (2017), a oferta dos cursos tecnológicos de moda foi regulamentada de forma precisa, deixando poucas margens para adaptações e/ou discussões sobre o seu funcionamento. Esta situação pode ser encarada como vantagem e desvantagem, mas facilita a implantação dos cursos - o que justifica os números revelados pela pesquisa.

A referida autora também levanta a hipótese de que a atenção ao "caráter artístico e quase genial da criação de moda" foi transferida para a fundamentação teórica e técnica. Desse modo, o aumento no interesse por implantar e cursar graduações tecnológicas não se relaciona apenas ao fato destes cursos serem "mais rápidos, mais 'baratos' e mais curtos. Também tem a ver com uma 'democratização, do campo de conhecimento e do acesso a este setor cada vez mais importante na economia brasileira" (BAGGIO, 2017, p. 14).

Os cursos tecnológicos, por definição, buscam articular os conteúdos à prática profissional, e a ligação entre estas graduações e seu direcionamento para o mercado de trabalho tem suscitado discussões no meio acadêmico. Borges (2017) afirma que a visão de se formar um profissional para atuar no mercado pode causar a impressão de que só existem habilidades técnicas, que poderiam ser adquiridas em cursos técnicos, livres ou de nível intermediário.

Assim, o curso superior tecnológico na área de Design de Moda precisa ir além do "saber fazer" e, principalmente, do privilégio do "fazer" sobre o "saber", pois as possibilidades de sucesso de uma carreira não são determinadas somente pelo preparo técnico. Há que se buscar uma sólida bagagem de conhecimento "teórico, técnico-científico, artístico e cultural, com foco no empreendedorismo e no desenvolvimento sustentável" [...] para formar profissionais aptos a participar, de forma estratégica, criativa e operacional das atividades relacionadas à área da moda em geral, valorizando a formação humana mais ampla (BORGES, 2017, p. 3). 
Outra discussão apresentada é a de que formar um perfil generalista de egresso pode levar à falta de aprofundamento nos conhecimentos recebidos, gerando problemas para o mercado e para a academia. No entanto, estes problemas não estão no caráter profissionalizante, mas podem estar na ausência de programas/rotas de articulação com o mercado, que promovam um processo educativo menos produtivista e mais transformador.

Por fim, Baggio (2017, p. 5) sustenta que essa não deve ser uma visão simplista de atender ao mercado, e sim uma busca pela "capacidade de articular conhecimentos multidisciplinares, teóricos e práticos, que somados podem diminuir a vulnerabilidade do indivíduo, aumentando a confiança e incitando à ação".

\subsection{As Carreiras na Área de Moda}

O estudo acadêmico de Moda é relativamente recente no Brasil, se compararmos aos países do hemisfério norte. Ainda assim, contamos com o maior número de cursos superiores na área em todo o mundo, conforme dados do Ministério da Educação. Contraditoriamente, persiste certo desconhecimento sobre as possibilidades profissionais no setor. Juntando-se a isso, há o problema da regulamentação da profissão de designer em um país onde na maior parte das denominações dos cursos figura o termo design.

Desde agosto de 2017, tramita, na Câmara dos Deputados, o Projeto de Lei 6808/17 que objetiva regulamentar a profissão de designer. Outro Projeto abordando a matéria foi aprovado pelo Congresso Nacional em 2015, tendo sido vetado pela Presidência da República, que alegou inconstitucionalidade. Conforme o veto, a regulamentação seria contrária ao artigo 5 da Constituição Federal, que assegura o livre exercício de qualquer trabalho, havendo restrições somente na possibilidade de dano à sociedade. Enquanto permanece o entrave legal, atividades profissionais e carreiras são construídas com base nas necessidades do mercado e do que se estuda na Academia.

Gustavsen e Yates (2013, p. 49), embora pensando em uma conjuntura internacional, organizaram um "Diretório de Carreiras" que, em parte, coadunase à realidade brasileira. A seleção divide-se em sete seções, com descrição das habilidades necessárias aos cargos, vantagens e desvantagens de cada um deles. O "diretório" não elenca só os trabalhos que dependeriam de formação superior em Design. Mesmo assim, ressalta-se o posicionamento das autoras de valorizar as formações na área, e de que quanto mais se começar "a trabalhar para um objetivo de carreira", mais cedo poderá se obter sucesso (GUSTAVSEN; YATES, 2013, p. 49). Em resumo, as carreiras estão enumeradas da seguinte forma: 
Figura 1 - Diretório de carreiras em moda.

\begin{abstract}
DESIGN
CARREIRAS EM MODA

Designer: de alta-costura; de prêt-a-porter; de fast-fashion; de marca própria; freelancer; contratado; de lingerie; de acessórios; de "acessórios leves"; de chapéus; de bolsas; de calçados; de jóias; de "outras especialidades". Tecnólogo de vestuário. Pesquisador de tendências.

\section{TÊXTIL}

Designer têxtil; designer de estamparia; designer de bordados; profissional de fiação e tecelagem; conservador têxtil.

\section{PRODUÇÃO}

Gerente de produção; técnico têxtil; modelista; graduador; enfestador; alfaiate; operador; tintureiro e colorista.

\section{FIGURINO}

Figurinista; assistente de figurino; supervisor de figurino; mestre de guardaroupa;

\section{VAREJO}

Assistente de vendas; gerente de loja; comprador; assistente de compras/auxiliar administrativo de compras; merchandiser; assistente de merchandiser; auxiliar administrativo de merchandiser; designer de varejo; visual merchandiser; personal shopper.

\section{COMUNICAÇÃO}

Relações-públicas de moda; profissional de marketing; fotógrafo de moda; assistente de fotografia; ilustrador; editor de revista; diretor de arte; produtor de fotografia; jornalista de moda; produtor de desfile; profissionais de cabelo e maquiagem; agente de modelos; modelo; stylist, "outras funções".

\section{ENSINO} técnico.

Professor; curador de moda; diretor de educação de museu de moda; arquivista;

Fonte: Resumo criado pelos autores a partir de: Gustavsen e Yates (2013, p. 52-185).

Entende-se a necessidade de analisar os contextos locais/regionais, e a realidade de cada mercado, porém a classificação acima e o posicionamento dos demais autores, por hora, nos fornecem elementos para conhecer as possibilidades profissionais na área. Diante disso, faz-se necessário compreender alguns conceitos relativos ao planejamento de carreira, a fim de relacioná-los aos objetivos da presente pesquisa.
\end{abstract}

\title{
30 PLANEJAMENTO DE CARREIRA
}

As transformações mercadológicas têm exigido dos currículos universitários a criação de disciplinas e a formação de novas competências. E é nessa era da gestão de competências que o planejamento da carreira pode incitar o estudante a refletir sobre sua própria vida, sendo importante não só na busca de objetivos profissionais, mas na satisfação pessoal. 
Segundo Dias (2016, p. 22), no Brasil há poucos trabalhos científicos sobre planejamento de carreira, enquanto em outros países ele é considerado um "bem público, ligado aos objetivos da política relacionados à aprendizagem, ao mercado de trabalho e à equidade social". Em se tratando de carreiras em Moda, campo de estudo relativamente novo no país, no qual muitas profissões ainda estão em regulamentação, essas pesquisas são ainda mais raras.

Entre os brasileiros em geral percebe-se uma dificuldade de fazer projeções sobre o seu futuro profissional. De acordo com Dutra (2017) o brasileiro tem problemas em "sonhar" a sua carreira e isto acontece porque raramente a planeja ou exercita projetar-se profissionalmente no futuro. Para o autor:

\begin{abstract}
As pessoas tendem a guiar suas carreiras mais por apelos externos, tais como remuneração, status, prestígio, etc. do que por preferências pessoais. Observamos, em nossas pesquisas, que o padrão cultural brasileiro é o de ser reativo quando se trata de sua carreira, tendendo a responder aos estímulos do mercado ou da empresa. Raramente o brasileiro pensa em sua carreira a partir de suas características ou preferências individuais (DUTRA, 2017, p.48).
\end{abstract}

Convém esclarecer que o termo carreira possui uma dimensão objetiva, que tem a ver com as atividades profissionais executadas em determinados períodos de tempo, relacionando-se ainda à regulamentação das profissões e à presença das organizações/empresas; e um aspecto subjetivo, relativo aos desejos, anseios e motivações profissionais do sujeito. Assim, chegamos a conceitos de planejamento de carreira que envolvem ambos os aspectos:

Incide em pensar quais as possibilidades de alcançar a carreira almejada, mesmo frente a grande competitividade e as ameaças do ambiente, definindo e adotando estratégias para o melhor aproveitamento das oportunidades. [...] O planejamento de carreira é, portanto, uma distinção permitida ao sujeito, capaz de estabelecer os passos a serem dados para alcançar um ou mais objetivos previamente determinados ou planejados. Planejar a carreira também é desenvolver uma missão, visão e valores que se voltem sobre as metas profissionais a serem atingidas a partir da realidade pessoal e profissional do sujeito (DIAS, 2016, p. 61).

Planejar a carreira consiste, portanto, em traçar objetivos pessoais e profissionais, e um plano para conseguir atingi-los. Os métodos utilizados variam, não existindo rigidez nos procedimentos e nem nas fases desse 
LIMA, Cláudia Cyléia de; et al.

processo. Mas quaisquer que sejam as metodologias adotadas e as suas etapas de execução, elas sempre passam pelo conhecimento do mercado de trabalho na área em que se pretende atuar e, principalmente, pelo autoconhecimento.

Desse modo, o planejamento pode ser desenvolvido pelo próprio sujeito ou com o auxílio de profissionais especializados, como psicólogos e orientadores profissionais/de carreira. Existem cursos específicos para formação de orientadores, entre os quais se destacam os oferecidos pelo Instituto do Ser, com sede em Florianópolis (SC) e turmas abertas em outras cidades brasileiras.

Nesse contexto, o planejamento de carreira começa a chamar atenção das instituições de ensino, nas quais já existem iniciativas para implantá-lo em currículos de nível médio e superior, no intuito de promover a aproximação do tema com os estudantes.

O Ensino Médio Invictus (EMI), instituição particular de São Luís (MA) estruturou um modelo curricular de orientação profissional (FROTA, 2017) com aulas semanais para as turmas de primeira, segunda e terceira séries do ensino médio, além de atendimento individualizado aos alunos. A matéria não gera nota, sendo feitas, ao final do semestre, a auto avaliação e a avaliação de todo o processo de orientação profissional.

Um exemplo no ensino superior é a disciplina Orientação e Planejamento de Carreira (OPC), oferecida desde 2003, em caráter optativo pelo Departamento de Psicologia da Universidade Federal de Santa Catarina, para graduandos da UFSC, independente da área de conhecimento. A experiência de Dias e Soares (2009) como professoras desta matéria resultou em um livro que discute, partindo dos depoimentos de alunos que frequentaram as aulas, a transição da escola para o mundo do trabalho, apresentando técnicas para que professores e formandos passem a refletir sobre os seus projetos profissionais.

A fase acadêmica foi apontada, pela maioria dos autores pesquisados, como o período oportuno para iniciar o planejamento, o que converge para as hipóteses levantadas no início do artigo. Por acontecer ao longo da vida, esta atenção à carreira acentua-se de acordo com as fases ultrapassadas pelo sujeito. E tende a se relacionar às situações de transição, como a passagem da universidade para o mercado de trabalho, quando, segundo Dias e Soares (2009) a maioria dos jovens sofrem com as poucas oportunidades.

$\mathrm{Na}$ bibliografia sobre o tema encontra-se com frequência o termo jovem, no entanto planejar a carreira não depende de idade, principalmente se pensarmos na quantidade de pessoas que fazem novas escolhas profissionais. A fase de graduação, independentemente da idade dos estudantes, assume um papel ainda mais importante em um país onde se costuma guiar a carreira por apelos externos. 
Outro ponto identificado na pesquisa bibliográfica diz respeito à associação do planejamento de carreira a uma "missão pessoal" ou "projeto de vida", como denomina Dias (2016, p.28). A pesquisadora esclarece que "aprender a planejar o futuro trabalho não se refere somente a uma carreira e a uma trajetória socioprofissional, mas à vida como um todo, porque a vida deve ser dotada de sentido e significado para além do trabalho".

\subsection{O Planejamento de Carreira em Moda}

De forma geral, no Brasil ainda são poucos os trabalhos científicos que abordam o planejamento de carreira. Na área do Design de Moda há raras publicações sobre esta temática, uma vez que os cursos se preocupam com as técnicas e o chamado "saber fazer".

No meio corporativo é pioneira e relevante a atuação da Fashion Career Counselor (Consultora de Carreira na área de Moda) Ângela Valiera, que há duas décadas presta consultoria, ministra aulas, palestras e treinamentos para profissionais, empresas, estudantes e recém-formados em cursos de Moda, destacando-se também na coordenação dos sites Carreira Fashion e Enmoda - Escola de Negócios de Moda. Nesse mesmo contexto, convém citar, ainda, o trabalho da Mentora de Carreiras e Negócios de Moda Caroline Amhof com alunos de Moda, empresários e novos empreendedores.

Já na modalidade de educação à distância ocorre o workshop online Empreendedorismo e Planejamento de Carreira em Moda. Promovido pela Escola de Negócios da Moda (Enmoda), tem o objetivo "orientar os participantes sobre como fazer a gestão da própria carreira de forma independente, assumindo o controle de sua vida profissional, adaptando e redirecionando seu planejamento sempre que necessário" (ENMODA, 2017). No conteúdo programático, a autoanálise profissional, o estabelecimento de metas a médio e longo prazo e a elaboração de planejamento de carreira.

A maioria das pesquisas científicas que de algum modo se articulam ao tema estão mais direcionadas à formação superior, à inserção dos egressos no mercado de trabalho e a percepção destes profissionais sobre a carreira escolhida. Por ter ligação com a finalidade deste artigo, destaca-se a perspectiva de Borges e Lima (2015), cuja Dissertação de Mestrado trata das representações sociais de alunos e professores de graduação sobre a Moda, e aponta que existe nestes sujeitos desapontamento quanto à atuação profissional.

Para Borges (2017), o perfil multitarefas da moda pode não demonstrar precisão no conjunto de habilidades desejadas do profissional que irá atuar no setor, acarretando o caráter generalista da formação, a fim de que o aluno seja exposto ao maior número possível de conhecimentos. O egresso, ao deparar 
LIMA, Cláudia Cyléia de; et al.

com o mercado, sente-se inseguro e pode até atribuir ao curso que fez a responsabilidade pela sua situação profissional desfavorável.

Diante de um entendimento equivocado da palavra moda, alguns cursos acabam direcionando os alunos para a área de criação do vestuário, sem levar em conta a realidade regional em que são oferecidos e reduzindo a atuação do designer de moda a fazer roupa. Este "direcionamento cego" para o mercado prejudica a formação, tornando-se pertinente:

[...] buscar reconhecer os diálogos que se estabelecem entre academia e mercado de trabalho, especialmente na atualidade, quando se tem a consciência da necessidade de interagir, construir e reconstruir, se necessário. As investigações poderão evidenciar melhores formas de interação entre as Instituições de Ensino Superior, o mercado de trabalho e os ingressantes, favorecendo o amadurecimento do setor, melhorando os currículos e diminuindo a evasão (BORGES, 2017, p. 11).

As turmas de graduação em Design de Moda no Piauí, conforme observações empíricas, costumam ser heterogêneas, com estudantes de idades e realidades diversas, desde aqueles que acabaram de sair do Ensino Médio aos já graduados em outras áreas, passando pelos que estão há um bom tempo sem estudar. Este é mais um aspecto a ser levado em conta para ensejar o desenvolvimento de atividades de planejamento de carreira.

A fim de verificar se estas atividades realmente são relevantes e necessárias a alunos e egressos de cursos superiores de Design de Moda no referido estado, realizou-se a pesquisa cujos resultados são expostos e analisados a seguir.

\section{PESQUISA DE CAMPO}

A pesquisa ocorreu entre março e setembro de 2017, período no qual foram analisadas as matrizes curriculares dos cursos de graduação em Moda existentes no Piauí e foi disponibilizado um questionário online. Os sujeitos constituíram-se na representação de amostragem intencional, definida por Lakatos e Marconi (2011) como método onde o pesquisador se interessa por ações e intenções de determinados elementos da população, no caso: alunos e egressos de Design de Moda, da capital e do interior do estado. 


\subsection{Resultados da Pesquisa Documental: Matrizes Curriculares dos Cursos de Moda}

Existem seis graduações em Moda atividade no estado. Para fins de melhor compreensão, aqui elas serão enumeradas por ordem de localização e ano em que foram implantadas.

Na capital, Teresina, funcionam: o Curso Superior de Tecnologia em Design de Moda do Centro Universitário UNINOVAFAPI (2008); o Bacharelado em Design da Moda e Estilismo na Universidade Federal - UFPI (2009); o Curso Superior de Tecnologia em Design de Moda do Instituto Federal de Educação, Ciência e Tecnologia do Piauí - IFPI Campus Teresina - Zona Sul (2017); e o Curso Superior Tecnológico em Design de Moda da Faculdade Facid Wyden (2017).

Em Parnaíba, litoral do estado, existe a Graduação Tecnológica em Design de Moda da FADIRE - Faculdade de Desenvolvimento e Integração Regional (2013). E na cidade de Piripiri, cerca de 165 km da capital, há o Curso Superior de Tecnologia em Design de Moda do IFPI Campus Piripiri (2016), no qual a autora da Dissertação trabalha como docente.

Além disso, existem turmas abertas em duas pós-graduações lato sensu na área, todas na capital: Negócios e Styling de Moda (UNINOVAFAPI) e Moda, Cultura e Mercado (FUNDELTA-FAR). Há previsão, ainda, de turmas nas especializações em Moda e Comunicação (UFPI), e em Criação e Produção em Moda (Facid Wyden). Tal quadro reflete o crescimento do mercado de moda no estado, o que leva as instituições a investir no setor, visando o retorno do público interessado.

A partir da observação das matrizes curriculares destas instituições, verificou-se que somente no curso de graduação da Faculdade Facid Wyden existe uma disciplina que menciona expressamente em seu título o termo "carreira". Trata-se de Estudos de Caso em Carreira e Empreendedorismo, com 60 horas aula, ministrada no primeiro semestre letivo.

Quanto aos programas voltados ao apoio profissional podemos citar o Centro de Carreira UNINOVAFAPI e o Carreiras, da Facid Wyden, para alunos de todos os cursos destas instituições. Entretanto, até a redação deste artigo, não havia no estado registros de trabalhos específicos em planejamento de carreira para a moda, cujo campo de atuação tem especificidades que precisam ser observadas e discutidas de forma particular.

Paralelamente a esta análise, buscou-se investigar, sob a perspectiva dos alunos e dos egressos formados no Piauí, se a ausência das disciplinas e atividades voltadas ao planejamento de carreira e ao mercado de Moda, 
LIMA, Cláudia Cyléia de; et al.

representa ou representou algum impacto na sua formação e nas suas percepções sobre as próprias carreiras profissionais. Os resultados obtidos a partir desta verificação encontram-se descritos a seguir.

\subsection{Resultados da Pesquisa de Campo: Questionário Online}

O questionário foi disponibilizado para alunos e egressos de todas as instituições que oferecem cursos superiores de Design de Moda no Piauí, ficando ativo entre março e setembro de 2017. Os voluntários foram convidados, via Internet, a responder 13 questões de múltipla escolha, com a possibilidade de acrescentar novas alternativas por meio da opção "outro".

Constatou-se equilíbrio quanto ao ano de formação dos participantes, havendo respostas de formados em 2010, quando a primeira turma de Moda colou grau, até recém-graduados, em 2017. Do total de 116 pessoas que contribuíram com a investigação, 67,3\% afirmaram atuar profissionalmente na área, somando-se a quantidade de empregados, consultores, freelancers, empresários ou professores. Os que não atuam alegaram decepção com a Moda $(8,6 \%)$ ou que estudam para concursos em outras áreas (6\%).

Quanto ao conhecimento sobre a graduação em Design de Moda e o mercado de trabalho, 30,2\% relataram ter buscado na Internet informações sobre a profissão antes de ingressar no ensino superior, enquanto 26,6 \% não sabiam como seria o curso e nem conheciam a configuração do mercado no início de suas graduações.

A ausência, ao longo do curso superior, de mais esclarecimentos sobre profissões na área de Moda foi apontada por 79,5\% dos voluntários, contabilizando os que declararam ter sentido "muita falta" ou um "pouco de falta" dessas orientações. Já 10,3\% dos participantes relataram não ter sentido esta deficiência, e 7,8\% afirmaram ter procurado por conta própria as informações a respeito.

Ainda sobre as orientações quanto ao mercado de trabalho e ao planejamento de carreira, $67,2 \%$ dos voluntários registraram que as suas escolas não dispunham de atividades específicas para isso, e que somente alguns professores falavam do assunto em sala de aula. Segundo $21,6 \%$ dos participantes, as instituições em que se formaram ou estudavam possuíam esse direcionamento, porém ele era oferecido com pouca frequência.

De acordo com $74,1 \%$ dos voluntários, o recebimento de informações sobre carreira e mercado teria feito diferença sobre as suas atuais situações profissionais, contra $23,3 \%$ que declararam ter buscado sozinhos a construção de suas carreiras. 
Em relação ao funcionamento do mercado de Moda no estado, 30\% consideram conhecer de forma geral e $28,4 \%$ indicaram um entendimento mais aprofundado. Os demais oscilam entre conhecer apenas os profissionais com quem trabalham e não conhecer devido à formatura recente. E 10,3\% disseram não ter conhecimento e nem ter ideia de por onde começar a obter tais subsídios.

Conforme 54,3\% das respostas, a carreira de Empresário/Empreendedor é considerada a mais promissora no estado, seguida pela de Professor (18,1\%), Modelista (9,5\%) e Designer contratado por marcas de moda (8,6\%). Embora empreender seja visto positivamente, $75 \%$ dos participantes afirmaram não o fazer, alegando como motivo as dificuldades financeiras.

Os participantes que se declararam empresários apontaram que, entre os problemas enfrentados no seu cotidiano de trabalho estão as finanças $(9,5 \%)$ ou a dificuldade de encontrar colaboradores especializados (9,5\%). Ainda nesse contexto, chamam atenção os 18,1\% que veem o empreendedorismo como um "privilégio de famílias ricas", e os 19,8\% que citam "falta de orientação" para começar a empreender.

Por fim, nas questões sobre satisfação profissional apenas 5,6\% afirmaram ter se decepcionado com a área e mudado de profissão. Desse modo, formandos e egressos mostram-se satisfeitos com a carreira. Porém, disseram precisar de "mais conhecimentos" para atuar profissionalmente o que demonstra a necessidade de orientações sobre carreira e mercado de trabalho ainda durante a graduação, no intuito de evitar prejuízos futuros.

\section{ANÁLISE DO DOS RESULTADOS DAS PESQUISAS}

Entende-se que está entre as atribuições das universidades e professores articular os conteúdos das disciplinas ao cotidiano das profissões. E que é papel dos alunos o empenho em construir e administrar os conhecimentos. Contudo, se os cursos superiores buscam a formação humana, social e profissional dos seus estudantes - e se a maioria das graduações se voltam ao mercado de trabalho - causam estranhamento os resultados das pesquisas.

Mesmo sendo impossível oferecer um curso que atenda a todas as demandas mercadológicas, especialmente de um setor onde se operam mudanças contínuas, constatou-se que as instituições de ensino superior do Piauí, ainda que preocupadas com um perfil de egresso apto às transformações de mercado, não privilegiaram em seus currículos a efetiva preparação do aluno para ser sujeito do planejamento de sua própria carreira. 
Isso pôde ser constatado pela quase inexistência de matérias que lidem diretamente com as temáticas de carreira. As particularidades dos cursos de graduação tecnológica já foram discutidas na fundamentação teórica e, em parte, podem explicar esta ausência. No entanto, não se trata apenas da duração dos cursos, variável entre dois e três anos, pois o Bacharelado existente no estado se desenvolve em nove semestres letivos e não contempla, em disciplina específica, as peculiaridades das carreiras em Moda.

A não regulamentação da profissão de Designer de Moda, bem como de outras no setor, também não pode ser apontada como motivo para não se debater as carreiras na universidade, pois o ato de planejar a carreira não é somente de ordem objetiva, está bem mais relacionado a aspectos subjetivos e motivacionais.

Além disso, a existência da disciplina optativa de Planejamento de Carreira oferecida pela UFSC aos alunos de todos os cursos da instituição demonstra que a falta de orientação dos estudantes sobre a futura profissão não é um "privilégio" dos discentes de Moda.

Em se tratando dos alunos e/ou egressos que responderam ao questionário verificou-se que a maioria ratifica a ausência das disciplinas ou atividades que tragam esclarecimentos sobre profissões, construção e planejamento de carreira na área de Moda. Também afirmam que as instituições onde estudam ou se formaram não dispunham destas atividades ou não as realizavam com frequência. Reforçando este entendimento, os voluntários acreditam que ter recebido essas informações durante a graduação faria diferença em suas atuais situações no mercado, conforme suposto nas hipóteses iniciais.

As respostas demonstram que são ofertadas poucas opções de formação complementar no estado. Na prática, esta é uma reclamação constante dos alunos, que poderá ser explicada em pesquisas futuras. Para o momento, faz-se necessário destacar que $80,2 \%$ dos participantes se declaram satisfeitos com a escolha da formação superior na área.

Entre os que se declararam satisfeitos, 50\% registraram que precisam de mais conhecimentos para atuar profissionalmente. Isso comprova a necessidade da familiarização com o que é o planejamento de carreira, a ser iniciado e praticado ainda na graduação, no intuito de evitar prejuízos futuros em nível pessoal, profissional e mercadológico. 


\section{CONSIDERAC̣ÕES FINAIS}

Entrecruzando a análise das grades curriculares dos cursos superiores e os dados do questionário aplicado, comprovam-se as hipóteses iniciais dessa pesquisa. Assim, pode-se afirmar que, no Piauí, a ausência de disciplinas ou atividades voltadas ao planejamento de carreira, executadas ao longo das graduações, compromete a formação do egresso capaz de compreender as relações entre universidade, conhecimento e mercado de trabalho.

Nesse contexto, constatou-se a necessidade e a relevância do planejamento de carreira para estudantes e egressos dos cursos de Design de Moda. Trata-se de uma carência que precisa ser sanada o mais rápido possível no âmbito das instituições, preferencialmente no decorrer da graduação, dados os quase dez anos em que profissionais têm se formado em Design de Moda no estado do Piauí.

No Brasil, de modo geral, instituições de ensino e alunos não são estimulados a pensar a carreira com frequência, a não ser em momentos de transição, como na passagem do ensino médio para o superior ou após a formatura. Ou até mesmo nas situações de crise, como no desemprego e na desilusão profissional, quando já ocorreram prejuízos materiais e psicológicos.

Conforme apurado ao longo deste artigo, planejar a carreira, preparando-se para circunstâncias favoráveis e desfavoráveis, pode minimizar riscos e frustrações profissionais e pessoais. Conhecer as áreas e possibilidades profissionais, bem como a prática e a realidade do mercado é de suma e urgente importância para os designers de moda em formação.

Assim, a partir do conteúdo apresentado e de outros estudos, desenvolvese uma pesquisa em nível de Mestrado, com o objetivo de sistematizar atividades de planejamento de carreira para um curso de graduação em Design de Moda em funcionamento no Piauí, no intuito de contribuir positivamente com a problemática apresentada.

\section{REFERÊNCIAS}

BAGGIO, Adriana Túlio. No design e no grau tecnológico: perfil e aspectos da formação em moda no Brasil. In: COLÓQUIO DE MODA, 13., 2017, Bauru. Apresentação de Trabalho... Bauru: FAPESP, 2017.

BORGES, Marcia de Souza. Problematizando a formação superior em moda. Revista dObra[s], São Paulo, v. 10, n. 21, p. 111-123, maio 2017.

BORGES, Marcia De Souza; LIMA, Rita de Cássia Pereira. Representações sociais e design de moda: reflexões sobre o ensino superior de Moda. In: COLÓQUIO DE MODA, 11., 2015. Anais ... Curitiba: Universidade Positivo, 2015. v. 1, p. 1-13. 
LIMA, Cláudia Cyléia de; et al.

DIAS, Maria Sara de Lima. Planejamento de carreira e projeto de vida. Curitiba: CRV, 2016.

DIAS, Maria Sara de Lima; SOARES, Dulce Helena Penna. Planejamento de carreira: uma orientação para estudantes universitários. São Paulo: Vetor, 2009.

DUTRA, Joel Souza. Gestão de carreiras: a pessoa, a organização e as oportunidades. 2. ed. São Paulo: Atlas, 2017.

ENMODA. Empreendedorismo e planejamento de carreira em moda.

Disponível em: <https://www.enmoda.com.br/curso/workshoponline-empree ndedorismoeplanejamentodecarreira>. Acesso em: 15 out. 2017.

FACULDADE DE DESENVOLVIMENTO E INTEGRAÇÃO REGIONAL. Design de moda. Disponível em: <http://graduacao.fadire.edu.br/courses/design-demoda/>. Acesso em: 12 out. 2017.

FACULDADE DEVRY FACID. Design de moda. Disponível em: <http://vpplan. devryone.com.br/radar/\#/course-portal/310>. Acesso em: 12 out. 2017.

FROTA, Anna Kelly Fraxe Tizzianel. Orientação profissional curricular: um modelo possível. In: LISBOA, Marilu Diez; SOARES, Dulce Helena Penna. Orientação profissional em ação: formação e prática de orientadores. São Paulo: Summus, 2017. p. 187-204.

GUSTAVSEN, Donna; YATES, Julia. Profissão moda: guia das 55 carreiras profissionais de maior futuro no mundo da moda. Tradução de Rita Andrade. São Paulo: G. Gili, 2013.

INSTITUTO FEDERAL DE EDUCAÇÃO, CIÊNCIA E TECNOLOGIA DO PIAUÍ. Projeto pedagógico do curso superior de tecnologia em design de moda: Campus Teresina Zona Sul. Disponível em: <http://libra.ifpi.edu.br/cursos/ documentos-dos-cursos/ppc/ppc-dsm-tzs.pdf>. Acesso em: 12 out. 2017.

INSTITUTO FEDERAL DE EDUCAÇÃO, CIÊNCIA E TECNOLOGIA DO PIAUÍ. Projeto pedagógico do curso superior de tecnologia em design de moda: Campus Piripiri. Piripiri (PI): Instituto Federal do Piauí, 2015.

LAKATOS, Eva Maria; MARCONI, Marina de Andrade. Fundamentos da metodologia científica. 6. ed. São Paulo: Atlas, 2011.

PIRES, Dorotéia Baduy. A história dos cursos de design de moda no Brasil. Revista Nexos: estudos em comunicação e educação, São Paulo, ano 6, n. 9, 2002.

PULS, Lourdes Maria. O design na formação de moda como campo de formação acadêmica. In: ENCUENTRO LATINOAMERICANO DE DISEÑO, 5., 2010, Buenos Aires. Anais... Buenos Aires: Universidad de Palermo, 2010.

UNIVERSIDADE FEDERAL DO PIAUÍ. Design da moda e estilismo.

Disponível em: <http://sigaa.ufpi.br/sigaa/public/curso/curriculo.jsf?lc=pt_ BR\&id=74141>. Acesso em: 12 out. 2017. 